\title{
SNAKES ON AN ISLAND: INDEPENDENT INTRODUCTIONS HAVE DIFFERENT POTENTIALS FOR INVASION
}

\author{
Monzón-Argüello, C. ${ }^{\text {ab }}$, Patiño-Martínez, C. ${ }^{b}$, Christiansen, F. ${ }^{c d}$, Gallo-Barneto, R. ${ }^{e}$, Cabrera- \\ Pérez, M.Á. ${ }^{f}$ Peña-Estévez, M.Á. ${ }^{g}$, López-Jurado, L.F. ${ }^{a}$, Lee, P.L.M. ${ }^{\text {ch }}$
}

\begin{abstract}
a Department of Biology, Campus de Tafira, Universidad de Las Palmas de Gran Canaria, Las Palmas, Spain
b Asociación para el Desarrollo Sostenible y Conservación de la Biodiversidad (ADS), C/Blas de Lezo 55, 1 G, Agüimes, Las Palmas, Spain

c Centre for Integrative Ecology, School of Life and Environmental Sciences, Deakin University, Warrnambool, VIC, Australia d Cetacean Research Unit, School of Veterinary and Life Sciences, Murdoch University, Murdoch, WA, Australia

e Área de Medio Ambiente. Gestión y Planeamiento Territorial y Ambiental (GesPlan S. A.), C/Francisco Gourié, 107 - $3^{\circ}$, Las Palmas, Spain

f Servicio de Biodiversidad. Dirección General de Protección de la Naturaleza, Gobierno de Canarias, C/Profesor Agustín Millares Carló, 18, 5 a planta, Edificio Servicios Múltiples II, Las Palmas, Spain

g Servicio de Medio Ambiente y Emergencias, Cabildo de Gran Canaria, Edificio Insular I, C/Profesor Agustín Millares Carlo, no 14 - $1^{\circ}$ Planta, Las Palmas, Spain

h Department of Biosciences, College of Science, Swansea University, Swansea, United Kingdom
\end{abstract}

\begin{abstract}
Snakes introduced to islands can be devastating to naïve native fauna. However, introduced populations must establish before range expansion (invasion) can occur. The factors that can determine successful invasion are those associated with the introduction event (e.g., characteristics of the founding population), the location (e.g., suitable environment and prey availability) and the species (e.g. life history characteristics). Here, we collected morphometric, ecological and genetic data on the recently introduced California Kingsnake (Lampropeltis californiae) in Gran Canaria. We found that snakes occurring at two locations a few $10 \mathrm{~s}$ of km apart do not represent the same population. Genetic analyses confirmed significant genetic difference $(F S T=0.184$; Dest $=0.341$ ), and that despite being inbred $(\mathrm{Fis}=0.245-0.257$ ) the populations had high levels of diversity ( $\mathrm{Ho}=0.485-0.490$; allelic richness $=4.875-6.364$ ). Snakes at the different Gran Canaria locations were significantly different in morphology (colouration, mass, length and age), fitness (egg production) and diet (rodents, skinks, lizards and geckos), supporting a hypothesis of separate founding groups in combination with local environmental heterogeneity leading to variation between these populations. We concluded that one population was more successful than the other in reproduction and recruitment, and may be having a greater impact on endemic reptiles. We recommend greater eradication effort for this population, as well as monitoring of local fauna at all locations to access the impact of predation.
\end{abstract}

